\title{
Evaluating temperature- and host-dependent reproduction in the parasitic freshwater mussel Unio crassus
}

\author{
Lea D. Schneider • P. Anders Nilsson • E. Martin Österling
}

Received: 30 June 2016/Revised: 22 March 2017/ Accepted: 22 April 2017/Published online: 11 May 2017

(C) The Author(s) 2017. This article is an open access publication

\begin{abstract}
Adaptation to temperature regimes and host presence may enhance fitness in parasites. In an experimental study, we evaluated the timing of glochidia release by Unio crassus subjected to three spring water temperature regimes in the presence and absence of the host fish Cottus gobio. The timing of glochidia release was delayed at $(i)$ constantly low temperatures $\left(<10^{\circ} \mathrm{C}\right)$, in contrast to earlier and pronounced releases at (ii) natural temperature increases that level off at intermediate temperatures $\left(10-15^{\circ} \mathrm{C}\right)$, and (iii) higher-than-normal temperatures $\left(10-20^{\circ} \mathrm{C}\right)$. Mussels from treatment $(i)$ that had not released glochidia during the experiment did so soon after being moved to the temperature in (ii), indicating a temperature threshold for glochidia release. Neither host fish presence nor the combined effect of temperature and host fish presence significantly affected the timing of glochidia release. The treatment with natural spring water temperatures indicated possible fitness
\end{abstract}

Guest editors: Manuel P. M. Lopes-Lima, Ronaldo G. Sousa, Lyuba E. Burlakova, Alexander Y. Karatayev \& Knut Mehler / Ecology and Conservation of Freshwater Bivalves

L. D. Schneider $(\bowtie) \cdot$ P. A. Nilsson · E. M. Österling Department of Environmental and Life Sciences Biology, Karlstad University, 65188 Karlstad, Sweden e-mail: lea.d.schneider@gmail.com

P. A. Nilsson

Department of Biology - Aquatic Ecology, Lund

University, Ecology Building, 22362 Lund, Sweden benefits for $U$. crassus through combined effects of high intensities of glochidia releases and high survival of released glochidia. The furthered understanding of climate change effects on mussel and host phenology in seasonal environments, potentially inducing temporal mismatches of glochidia release to host availability, is key to mussel conservation.

Keywords Freshwater mussel conservation . Glochidia release $\cdot$ Glochidia survival $\cdot$ Temperature fluctuations

\section{Introduction}

In seasonal environments, organisms have adapted to synchronize life history with favourable environmental conditions (Lack, 1950; Cohen, 1976; Galbraith \& Vaughn, 2009). For example, animals may use temperature increase in spring to time reproduction with peaks of food availability to maximize their fitness (Visser et al., 1998; Bradshaw et al., 2004). The strong selection pressure to track such resources can drive phenological adaptation (Lieth, 1974; Hipfner, 2008). Recently, gradual changes in spring temperature development, caused by climate change, have induced shifts in species' phenology, where e.g. migration, reproduction, bud burst, or flowering occur two weeks earlier today compared to during the 1960s (Stenseth $\&$ Mysterud, 2002). 
In more complex species interactions, such as hostparasite systems, directional temperature changes resulting in phenological shifts can cause mismatches between parasites and their resources (Cushing, 1990; Poulin, 2007). Reduced host availability during parasite reproduction can result in negative fitness consequences for parasites (Walther et al., 2002; Paull \& Johnson, 2014; Altman et al., 2016). Thus, mechanisms enabling parasites to track hosts should enhance host infection and parasite fitness (Haas, 2003; Runyon et al., 2006; Brooks \& Hoberg, 2007; Mordue (Luntz) $\&$ Birkett, 2009). This is particularly true for parasites using poikilothermic hosts in environments with large thermal variability (Poulin, 2007).

The unionoid freshwater mussels have a life cycle that includes a parasitic stage on fish (Strayer et al., 2004). Temperature has been proposed a major factor affecting the timing of mussel reproduction, including larval (glochidia) release by gravid mussels (Davenport \& Warmuth, 1965; Young \& Williams, 1984; Watters \& O'Dee, 2000; Hastie \& Young, 2003; Österling, 2015). Host fish presence can also be affected by temperature, and is critical for mussel reproductive success (Davenport \& Warmuth, 1965; Hochwald, 1997; Bauer \& Wächtler, 2001; Österling et al., 2008; Pandolfo et al., 2012). Previous studies have suggested chemical and mechanical cues from host fish as triggers initiating glochidia release (Meyers \& Millemann, 1977; Jokela \& Palokangas, 1993; Welte, 1999; Haag \& Warren, 2000). However, combined effects of water temperature and host fish presence have, to our knowledge, hitherto not been evaluated (Young \& Williams, 1984).

The thick-shelled river mussel Unio crassus is one of Europe's most endangered freshwater mussel species (Bjelke et al., 2010; Lopes-Lima et al., 2017). The mussel starts reproducing when water temperature rises during spring (mid April to early May in Sweden, personal observation). We aimed to evaluate how water temperature and host fish presence affected the timing and probability of glochidia release by $U$. crassus during spring conditions. We tested this experimentally for three different temperature scenarios in the presence or absence of host fish (bullhead, Cottus gobio), where (i) water temperature was kept constantly low over the experiment period, (ii) the temperature regime resembled the conditions in the river where mussels and fish originated, i.e. the water temperature followed a natural spring temperature increase levelling off at an intermediate constant temperature until the end of the experiment, and (iii) the water temperature increased at high rate levelling off at a higher-than-normal spring water temperature. We predicted that gravid mussels in the natural temperature scenario should release their glochidia earlier in the presence than in the absence of host fish, while temperature-driven effects on glochidia release should occur at spring temperature patterns different from normal. For mussels at natural temperatures, we also predicted that (1) more mussels release glochidia, (2) fewer mussels abort broods, and (3) the released glochidia survive longer compared to mussels from the high temperature scenario.

\section{Materials and methods}

Collection and maintenance of study organisms

Mussels and fish were collected in the river Tommarpsån (WGS84 55 $33^{\prime} 0.3^{\prime \prime} \mathrm{N} 14^{\circ} 8^{\prime} 25.1^{\prime \prime} \mathrm{E}$ ) in southern Sweden on 22 April 2014, when stream temperature was $10^{\circ} \mathrm{C}$. Mussels of similar length (mean \pm standard deviation, SD: $6.9 \pm 0.5 \mathrm{~cm}$ ) that were fully gravid, i.e. with marsupia packed with glochidia (Österling et al., 2008), were transported to the lab facility at Lund University. The mussels were placed in aerated 201 plastic aquaria (Faunarium PT2265, Exo Terra) in groups of five individuals, and were acclimated for 8 days in dechlorinated, copper-free tap water at $10^{\circ} \mathrm{C}$, exchanged daily, and a $10 \mathrm{~h}: 14 \mathrm{~h}$ dark:light photoperiod. On 30 April, individual mussels were transferred to identical aquaria used for experiments, where the mussels were fed (Nanno 3600, Instant $\mathrm{Algae}^{\circledR}$ ) and water was exchanged daily.

Bullhead (C. gobio) was collected by electrofishing (L-600 flat DC, Lug AB). A subsample of the fish was anaesthetized in the field (Benzocaine, $<10 \mathrm{mg} / \mathrm{l}$ ) and visually inspected for glochidia infestation using a binocular microscope (MZ6, Leica). No glochidia were detected on the fish gills indicating that mussels had not yet initiated the seasonal glochidia release. The remaining fish were transported to the aquaria lab facility in aerated tanks, and were acclimated to tap water $\left(10^{\circ} \mathrm{C}\right)$ in 1601 glass aquaria fit with external water filters (Classic 600, Eheim). The fish were fed with frozen gammarids until the start of the experiment on 1 May. The fish were not fed during the 
experiments to avoid fish faeces impairing the survival of released glochidia.

\section{Study design}

The timing and probability of glochidia release of $U$. crassus was investigated at LOW, NATURAL, and HIGH temperatures (temperature regimes presented below), in the PRESENCE or ABSENCE of the host fish $C$. gobio. Each temperature scenario included twelve replicate aquaria (20 1), each supplied with one gravid mussel $15 \mathrm{~h}$ before the start of the experiment, and with three individuals of $C$. gobio (mean length \pm SD: $5.1 \pm 2.0 \mathrm{~cm}$ ) in six of those replicate aquaria (fish PRESENCE) added $15 \mathrm{~min}$ before the start of the experiment. Two of the LOW aquaria (LOW-PRESENCE and LOW-ABSENCE) were excluded because of spontaneous glochidia releases prior to the start of the experiment. One mussel (NATURAL-PRESENCE) was gravid on only one side of the gill, but was considered in experimental gravidity controls when evaluating glochidia release intensities.

Larval release can be regulated by the accumulated number of degree days (Young \& Williams, 1984; Hastie \& Young, 2003; Galbraith \& Vaughn, 2009; Österling, 2015). Thus, we ran the experiments until the accumulated degree days in a treatment with low glochidia release reached or exceeded the accumulated degree days in treatments where the majority of mussels had released or aborted their brood.

\section{Water temperature}

The temperature in the LOW treatment was regulated by air coolers (KBFL, Asarums Industri AB) set to $10^{\circ} \mathrm{C}$, which maintained the water temperature at $8.4 \pm 0.4^{\circ} \mathrm{C}$ (mean $\pm \mathrm{SD}$ ) over the experiment period. The temperature in the NATURAL treatment, which was regulated using a control unit (T-Control Pro, Dupla) coupled with aquarium heaters (Thermocontrol 75, Eheim), increased from $10.0^{\circ} \mathrm{C}$ to $14.4 \pm 1.2^{\circ} \mathrm{C}$ (raised $0.5^{\circ} \mathrm{C}$ per day) over the first ten experimental days, mimicking the natural spring temperatures in Tommarpsån (temperature increase from $8.9 \pm 1.3^{\circ} \mathrm{C}$ to $14.0 \pm 2.1^{\circ} \mathrm{C}$ between April and May), and was kept at $14.4 \pm 0.9^{\circ} \mathrm{C}$ afterwards. In the HIGH treatment, also regulated using a control unit and aquarium heaters, temperature increased from $10.0^{\circ} \mathrm{C}$ to $19.3 \pm 1.3^{\circ} \mathrm{C}$ (raised $1^{\circ} \mathrm{C}$ per day) during the first ten experimental days and stayed at $19.2 \pm 0.1^{\circ} \mathrm{C}$ afterwards (Fig. 1). Insulation (Styrofoam plates, Therm 399 EPS, Weber Saint-Gobain) was fitted to enhance temperature stability in aquaria.

Investigations of mussel brood releases and survival of glochidia

Mussels were examined for releases of glochidia and abortions at 9:30 am, 13:30, and 17:30 daily. While a glochidia release event was defined as release of fully vital glochidia, any exposal of undeveloped eggs or mussel larvae was categorized as abortion. The intensity of every glochidia release and abortion event was graded from " 0 " to " 3 " and " 0 " to " -3 ", respectively, representing no release/abortion (0), minor release/abortion (1/-1), major release/abortion $(2 /-2)$, and complete brood release/abortion with no remaining brood in the marsupium (3/-3). To confirm this grading, the outer gill arches, used as marsupium in $U$. crassus, were visually inspected after each release/abortion event. When the marsupium was full of brood, i.e. overall swollen and white or orange in colour, the intensity of brood release was judged as " 0 ". Intensity " $3 /-3$ " was approved when the outer gills were flat and transparent. Intensities " $1 /-1$ " and " $2 /-2$ " were confirmed when the marsupium was filled with brood $\geq 50 \%$ and $<50 \%$, respectively. Mussels that had released all brood were removed from the experiment, acclimated to stream water, and returned to Tommarpsån.

The survival of released glochidia was monitored once every $24 \mathrm{~h}$, and followed until all glochidia were found dead in an aquarium or experimental day 18 was reached. To evaluate survival, three subsamples of glochidia from each aquarium, 0.1-2 $\mathrm{ml}$ each, were placed in Petri dishes with water. The numbers of glochidia with open or closed valves were counted, using binocular microscopes, before and after a weak $\mathrm{NaCl}$ solution, stimulating the glochidia to close their valves, was added to the dishes (Fritts et al., 2014).

Extended test for glochidia release

Mussels in the LOW temperature treatment that had not released any brood on the last investigation on day 18 were transferred to newly set up aquaria at NATURAL temperatures $\left(14.1 \pm 1.1^{\circ} \mathrm{C}, \quad\right.$ mean $\left.\pm \mathrm{SD}\right)$ and 


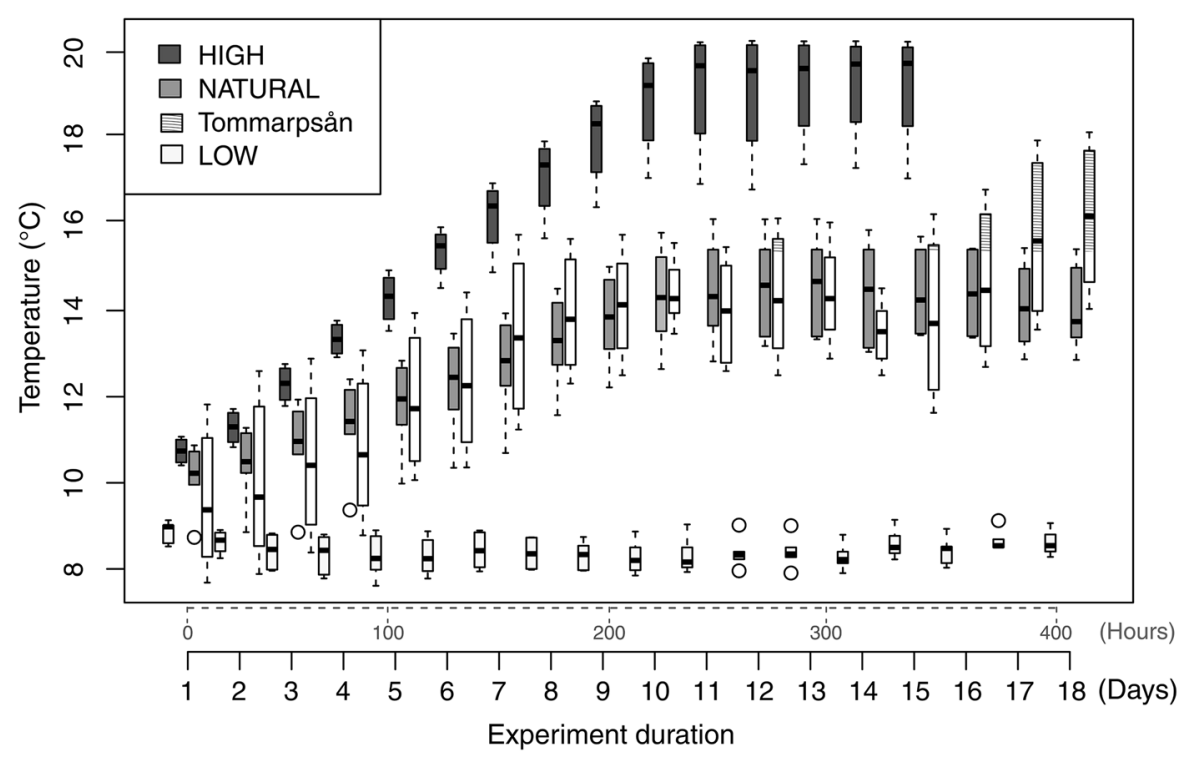

Fig. 1 Average water temperatures $\left({ }^{\circ} \mathrm{C}\right)$ in aquaria of the LOW, NATURAL, and HIGH temperature treatments (open, light grey, and dark grey boxplots), and in the stream Tommarpsån in May 2013 (striped boxplots). The time in

glochidia release was monitored as above. This was done to evaluate if mussels can keep their broods until favourable or possible threshold temperatures are reached (Trübsbach, 1998; Watters, 2000; Blažek \& Gelnar, 2006).

\section{Data analysis}

The timing of release events was calculated in hours to release/abortion for every mussel tank (0-412 h). If a mussel did not release or abort its brood during the experiment, it was assigned $412 \mathrm{~h}$ as a ceiling value. As we were interested in the release timing, the first release events were used in the analyses. However, three of the mussels released only minimal amounts of glochidia/eggs in their first release, i.e. considerably fewer glochidia/eggs than other releases/abortions categorized as "few". To be consistent in the categorization of brood releases, the second events for these three mussels, which were full brood releases, were used in the analyses. One additional mussel had one minor and one much more distinct abortion, and we chose the second event for analysis following the reasoning above. Non-parametric, two-way ScheirerRay-Hare (SRH) tests (Dytham, 2011) evaluated how "hours to release/abortion" was affected by factors "temperature treatment" (LOW, NATURAL, HIGH) experiment equals the experimental days and the days in the month May (1-18), when stream temperatures were measured in 2013. The numbers 0-400 represent experimental hours with start 1 May 2014. Circles denote outliers from the boxplots

and "host fish presence/absence" (PRESENCE, ABSENCE). Mann-Whitney U-tests with Bonferroni correction were used for post-hoc evaluation of significant differences between the three temperature treatments. Even if the full SRH model is the primary focus of our experimental design and data interpretation, we also compared glochidia release timing after excluding an early glochidia release, observed at NATURAL temperatures in host ABSENCE. We justify this based on previous experiences of difficulties of keeping high numbers of gravid mussels in captivity without early, spontaneous glochidia release. The categorized intensities of glochidia releases $(0$ to 3)/abortions ( -3 to 0 ) were evaluated by Ordered logistic regressions with factors "temperature treatment" and "host presence/absence". The survival of released glochidia was evaluated using Kaplan-Meier and Cox regression analyses for the three temperature treatments, using the survfit() and $\operatorname{coxph}()$ functions in the $\mathrm{R}$ package survival, based on mussel aquaria level with events occurring when all glochidia were found dead in the three subsamples taken for daily glochidia survival investigation. Right censored data occurred in the survival analysis at post-release day 12 and 14 (Fig. 4), as some glochidia survived until the final experimental day 18. All statistical analyses were performed in R studio version 0.98.501 (2016 The R 
Foundation for Statistical Computing) or IBM SPSS statistics version 22.0.0.2.

\section{Results}

Timing of glochidia releases and abortions

The timing of glochidia releases differed significantly between the three temperature treatments (ScheirerRay-Hare (SRH) test: $S S=1078.9, \quad H=11.2$, df $=2, P<0.001$, Fig. 2a). Mussels kept at LOW temperatures released glochidia after $355.8 \pm 119.2$ (mean $\pm \mathrm{SD}$ ) hours, which was significantly later than mussels kept at HIGH (168.9 $\pm 96.2 \mathrm{~h}$; Mann-Whitney U-test (MWU): $W=109.5, P=0.006$ ) and NATURAL temperatures $(251.2 \pm 86.8 \mathrm{~h}$; MWU: $W=99, P=0.01$ ), including ceiling values. Neither host fish PRESENCE (SRH test: $S S=51.8, H=0.54$, $P=0.46)$ nor the interaction term between host fish PRESENCE and temperature (SRH test: $S S=24.4$, $H=0.25, P=0.62$ ) significantly affected the timing of glochidia releases. However, a majority of mussels kept at NATURAL water temperatures in host ABSENCE released glochidia later $(308.2 \pm 87.7 \mathrm{~h}$ to release) than at host PRESENCE (at $203.7 \pm 87.7 \mathrm{~h}$

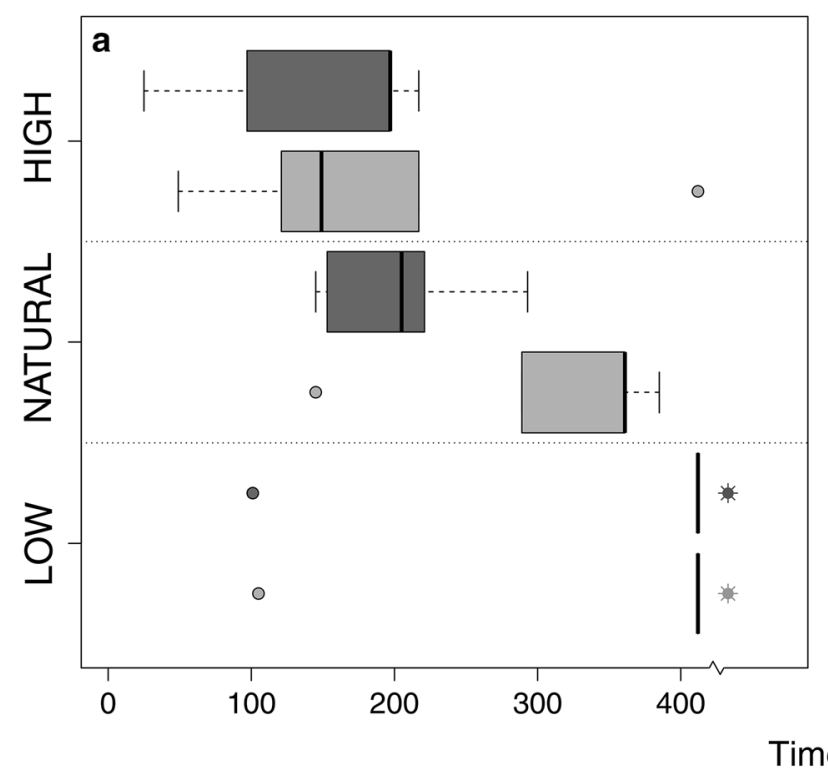

Fig. 2 a Hours to glochidia release and $\mathbf{b}$ to abortion in mussel tanks ( $\mathbf{a} n=34 ; \mathbf{b} n=34$ ) of the LOW, NATURAL and HIGH temperature treatment, in host fish PRESENCE (dark grey) or ABSENCE (light grey). Stars * indicate spontaneous post- to release). This difference was not statistically significant (MWU, $W=23.5, P=0.14$ ), but may still be of biological importance. Although highly speculative, we make this side note because of a significant difference between host PRESENCE and ABSENCE (MWU, $W=23, P=0.03$ ), when the only mussel individual that spontaneously carried out an early glochidia release in host ABSENCE at NATURAL temperatures was removed from the analysis (Fig. 2a).

There were no effects of temperature (SRH test, $S S=28.9, H=0.42$, df $=2, P=0.52$ ), host fish presence (SRH test, $S S=190.1, H=2.78$, df $=1$, $P=0.10)$ or a combined effect of temperature and host fish presence (SRH test, $S S=98.1, H=1.43$, $\mathrm{df}=2, P=0.23$ ) on the timing of abortions (Fig. 2b). However, most brood releases occurred at NATURAL and HIGH temperatures, and fewest at LOW temperatures. Higher proportions of abortions occurred in host ABSENCE than in host PRESENCE for all temperature treatments, and in total, mussels at HIGH temperatures had the highest proportions of abortions compared to mussels in the NATURAL and LOW temperature treatments (Table 1). Fully developed and vital glochidia were released by $13 \%$ of the mussels at LOW temperature after they were transferred to NATURAL temperatures (Table 1 and Fig. 2a).

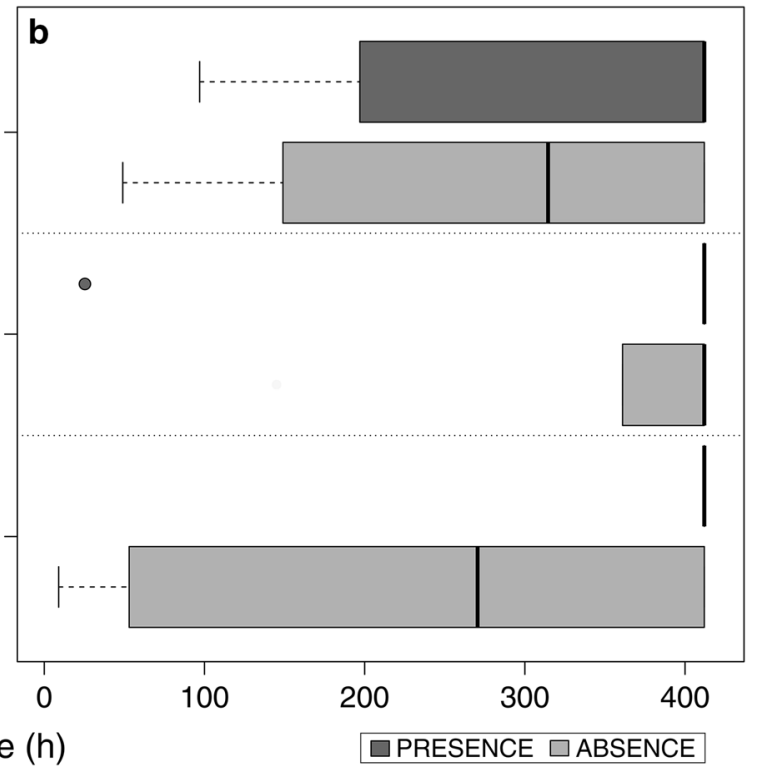

experimental glochidia releases after LOW mussels without release event until day 18 were transferred to NATURAL temperatures. Circles denote outliers from the boxplots 
Intensity of glochidia releases and abortions

Temperature had a significant effect on the probability of glochidia release intensity (Ordered logistic regression (OLR): Wald $X_{2}^{2}=15.48, P=0.01$ ). Highintensity glochidia releases were more likely to occur at NATURAL and HIGH temperatures than at LOW temperatures (OLR: Wald $X_{1}^{2}=7.01, P=0.01$, Fig. 3). There were no effects of host fish presence (OLR: Wald $X_{1}^{2}=0.58, P=0.45$ ) or the interaction term between host presence and temperature (OLR: Wald $X_{2}^{2}=0.28, P=0.87$ ). Many abortions with high scores occurred at LOW and HIGH temperatures, although the probability of abortion intensities did not differ significantly between temperature treatments (OLR: Wald $X_{2}^{2}=1.33, P=0.52$ ), host fish presence (OLR: Wald $X_{1}^{2}<0.01, P=0.99$ ), or for the interaction between the factors (OLR: Wald $X_{2}^{2}=0.06$, $P=0.97)$.

Survival of released glochidia

Glochidia that were released in the LOW temperatures treatment had a survival time of $9.0 \pm 5.0$ days (mean $\pm \mathrm{SD}$ ). These glochidia originated from only two individual mussels, which is why the LOW

Table 1 Proportions (\%) and total number (Total no.) of mussels that carried out glochidia releases (Release) and abortions (Abortion) in the presence (P) and absence (A) of fish in the HIGH, NATURAL, and LOW temperature treatments, and in the extended test where mussels were relocated from LOW to NATURAL temperature treatment

\begin{tabular}{llll}
\hline Treatment & $\begin{array}{l}\text { Release } \\
(\%)\end{array}$ & $\begin{array}{l}\text { Abortion } \\
\%\end{array}$ & $\begin{array}{l}\text { Total } \\
\text { No. }\end{array}$ \\
\hline High & & 17 & 12 \\
P & 50 & 25 & \\
A & 42 & 9 & 11 \\
Natural & & 18 & \\
P & 55 & & \\
A & 45 & 0 & 11 \\
Low & & 27 & \\
P & 9 & & \\
A & 9 & 0 & \\
Low to natural & & 0 & \\
P & 13 & & \\
A & 13 & & \\
\hline
\end{tabular}

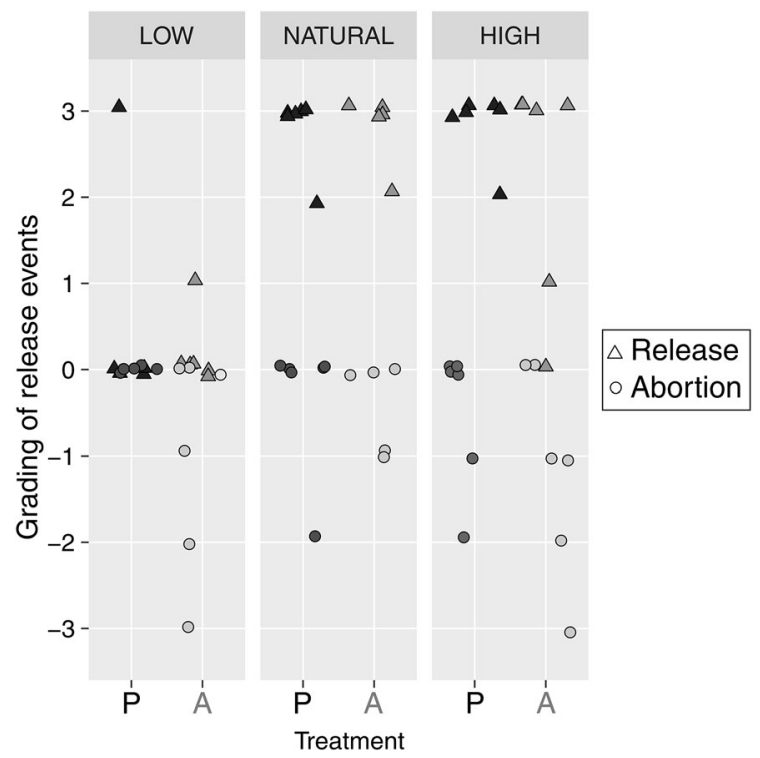

Fig. 3 Distribution of release events in the LOW, NATURAL, and HIGH temperature treatments, in host fish PRESENCE ( $P$ dark colour) or ABSENCE ( $A$ light colour), illustrating raw data of the grading of glochidia releases (triangles, positive grades: $0-3, n=34$ ) and abortions (circles, negative grades: -3 to $0, n=34$ ). Grade 0 represents no release event, grade 3 a complete glochidia release, and grade -3 an abortion of all brood. Data points are displaced for clarity

temperature treatment was excluded from the following survival analysis. Log-rank test showed that the survival curves of glochidia at NATURAL and HIGH temperatures varied significantly (Survdiff: $X^{2}=5.8$, $\mathrm{df}=1, P=0.02$ ) due to a higher probability of glochidia survival at NATURAL temperatures (mean $\pm \mathrm{SD}: 6.5 \pm 3.3$ days) compared to $\mathrm{HIGH}$ temperatures ( $6.0 \pm 1.2$ days; Cox proportional hazard: likelihood ratio test $=6.22, \mathrm{df}=1, P=0.01$, $n=22$, number of events $=15$; death-hazard ratio 1.42 times lower at NATURAL than at HIGH temperatures, Fig. 4).

\section{Discussion}

The results of our study suggest that mussel reproduction is adapted to local spring water temperature, where deviations from normal temperature may impair mussel recruitment. Constant LOW spring water temperature significantly delayed glochidia release in $U$. crassus compared to the NATURAL and HIGH temperature scenarios, where earlier 


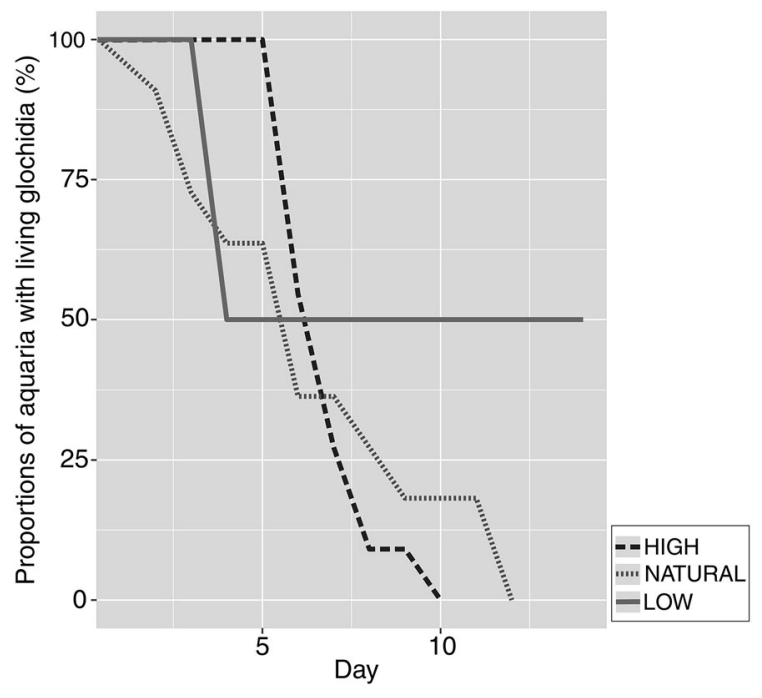

Fig. 4 Proportions (\%) of aquaria (HIGH, $n=11$; NATURAL, $n=11$; LOW, $n=2$ ) with living glochidia at days post release

glochidia release occurred with higher probability and intensity, possibly triggered by a temperature threshold. Survival of released glochidia was higher at NATURAL than at HIGH spring water temperatures, suggesting higher encounter-rate potential between glochidia and host fish, possibly leading to higher infestation rates and juvenile mussel recruitment at natural than at high water temperature during spring.

Temperature affecting timing and probability of glochidia releases

A thermal summation effect (degree days) is one suggested mechanism behind the timing of brood release in unionoid mussels (Davenport \& Warmuth, 1965; Young \& Williams, 1984; Hastie \& Young, 2003; Galbraith \& Vaughn, 2009; Österling, 2015). Our results do not support such an effect, but suggest temperature thresholds affecting the timing and probability of glochidia release by $U$. crassus (Trübsbach, 1998; Watters, 2000; Blažek \& Gelnar, 2006). We conclude this because mussels kept at NATURAL and $\mathrm{HIGH}$ temperature carried out glochidia releases at similar accumulated degree days, whereas most mussels at LOW temperature did not (Jansen et al., 2001). Fully viable glochidia were however suddenly released after mussels being transferred to natural temperatures. This suggests that $U$. crassus is able to keep viable brood for at least three weeks to match glochidia release with beneficial thermal conditions (Lang, 1998) above temperature thresholds of around $15^{\circ} \mathrm{C}$. These quick glochidia releases after the sudden temperature shift may be an intuitive reaction to respiratory trade-offs in gravid mussels (Tankersley \& Dimock, 1993; Trübsbach, 1998; Aldridge \& McIvor, 2003; Ganser et al., 2015). Such trade-offs may also be the underlying mechanism of brood abortions in our simulation of higher-than-normal water temperature increase in spring. We do not believe that these brood abortions were linked with handling stress of mussels when carefully opened to examine the marsupial brood content as mussels released all brood at a first or at a second event latest, indicating that two brood examinations were conducted per mussel at a maximum. However, abortions may enhance lifetime reproductive success, as high temperatures can reduce survival of gravid mussels (Aldridge \& McIvor, 2003).

Host presence and glochidia survival

Host-recognition mechanisms are common among parasites, and responses to fish have been described for some unionoid mussels (Jokela \& Palokangas, 1993; Teutsch, 1997; Trübsbach, 1998; Welte, 1999). In our study, neither host fish presence nor the combined effect of temperature treatment and host fish presence, significantly affected the timing of glochidia release. Although our statistical results do not support the influence of host fish presence on glochidia release, we still observed that $80 \%$ of the mussels kept at natural water temperatures without host fish released glochidia later than when hosts were present. Therefore, the biological relevance of host fish presence should not be excluded. Further investigations could consider effects of different host fish species and mussel populations from a variety of local thermal conditions on glochidia release.

The survival of released glochidia followed drop offs observed for other mussel species (Zimmerman \& Neves, 2002; Cope et al., 2008). Elevated temperatures may possibly affect metabolic rates and result in short-lived glochidia, as seen in the HIGH temperature scenario (Teutsch, 1997; Jansen et al., 2001; Pandolfo et al., 2010). This is supported by a prolonged glochidia survival at LOW temperatures. We however propose that the higher number of released glochidia at NATURAL temperature regimes can result in more 
host infestations, even if we did not evaluate glochidia viability thresholds (e.g. American Society for Testing and Materials (ASTM), 2013; Fritts et al., 2014). Fitness benefits may still occur within optimal temperature ranges if only some of the many glochidia released at natural river temperatures attach to fish and successfully metamorphose to juveniles (Roberts \& Barnhart, 1999; Galbraith et al., 2012; Zimmerman \& Neves, 2002; Taeubert et al., 2014).

Consequences for mussel-host interactions and mussel recruitment

Temperature fluctuations are predicted to occur more frequently in the future, exceeding the range of natural thermal variation (Menzel et al., 2005; IPCC, 2014). Such temperature changes have been suggested to cause mismatches between mussel reproduction and host availability (Hastie \& Young, 2003; Cosgrove et al., 2012; Pandolfo et al., 2012). Low temperatures can delay glochidia releases, as indicated by our results, but can also disrupt the gametogenic cycle and result in impeded mussel reproduction (Heinricher \& Layzer, 1999). Our results further suggest that high rises in temperature may trigger early and sudden glochidia releases, corroborating the results of Trübsbach (1998) and Hastie \& Young (2003). Although mussels with host-recognition ability may be able to synchronize reproduction to host presence in fluctuating environments, respiratory trade-offs at high temperatures may still lead to uncontrolled brood releases, and impede any brood-keeping strategy and host-directed glochidia release.

Mismatches in mussel-host interactions may also increase when shifts in host phenology or host range occur, or when host populations decline as a result of climate change (Hastie \& Young, 2003; Pandolfo et al., 2012). The magnitude may depend on speciesspecific thermal tolerances or abilities for acclimation and adaptation (Reyjol et al., 2009). Compelling evidence shows that fluctuating temperatures can affect the reproduction timing and success of a variety of fish species (Pankhurst \& King, 2010; Pankhurst \& Munday, 2011; Crozier \& Hutchings, 2014), including hosts of $U$. crassus (Dorts et al., 2012; Domagała et al., 2013). Host extinctions may occur in species with limited migratory and range-change potential (Walther et al., 2002), potentially reducing host availability for $U$. crassus. Observed range expansions and migrations of freshwater fish, both in upstream and downstream directions (Comte \& Grenouillet, 2013), could also cause spatial mismatches for $U$. crassus, if fish respond quickly to temperature changes by leaving former home ranges. The generally low migration potential of mussels makes them vulnerable to range shifts of their hosts, particularly in upstream direction (Pandolfo et al., 2012). Repeated spawning by mussels, including $U$. crassus, may reduce the risk of temporal mismatch to hosts (Cushing, 1990; Hochwald, 1997), and host shifts or host-range expansions could evolve over time (Poulin, 2007). The long generation times of mussels may however reduce the potential for such adaptions to occur, if host species respond quickly to environmental change (Daraio et al., 2014). This highlights the sensitivity of threatened unionoid mussels with complex life cycles.

\section{Conclusion and applications for conservation}

Unionoid mussels are one of the most imperilled groups of organisms worldwide, with ongoing extinctions, and forecasted climate fluctuations pose additional challenges to their complex life cycles (Strayer et al., 2004; Bogan, 2008; Lydeard et al., 2004). We believe that our study points out possible future phenological shifts in mussels, affecting conservation concerns. Here, it is important to consider potential changes in host phenology and home range, as well as host declines, resulting in temporal and/or spatial host absence during mussel reproduction (Zale \& Neves, 1982). This latter aspect may be critical for U. crassus, although mismatches may be compensated by $U$. crassus asynchronous and multiple spawning each year (Hochwald, 1997), while mismatches may be particularly challenging for mussel species that spawn only once per year and synchronously within the population, e.g. Margaritifera margaritifera (Hastie \& Young, 2003). For conservation incentives, it is moreover difficult to match conservation measures, such as artificial host fish infestations, to timing of mussel reproduction, glochidia release, and host fish presence. Reduced glochidia survival and vitality at elevated temperatures pose further challenges for mussel rearing and re-introduction activities (Zimmerman \& Neves, 2002). Lastly, re-introduction and translocation of mussels can hinder population declines. However, according to our study, this should 
not be conducted without predictions of mussel phenology and host fish interactions. Thus, understanding effects of temperature and host fish composition in time and space can help forecast the success of conservation measures.

Acknowledgements We would like to thank K. Wutz for field and laboratory assistance and I. Olsson for enabling this study within the European LIFE project UC for LIFE. Funding was provided by the European Commission's LIFE program fund (LIFE10 NAT/SE/000046), FORTUM Nordic Environmental Fund, and the NGO Swedish Society for Nature Conservation (SSNC). The investigation was performed in accordance with the Swedish law, and was approved by the Ethical Committee for Animal Experiments in Malmö/Lund (permission number M111-12) and the Administrative County Board of Skåne.

Open Access This article is distributed under the terms of the Creative Commons Attribution 4.0 International License (http:// creativecommons.org/licenses/by/4.0/), which permits unrestricted use, distribution, and reproduction in any medium, provided you give appropriate credit to the original author(s) and the source, provide a link to the Creative Commons license, and indicate if changes were made.

\section{References}

Aldridge, D. C. \& A. McIvor, 2003. Gill evacuation and release of glochidia by Unio pictorum and Unio tumidus (Bivalvia: Unionidae) under thermal and hypoxic stress. Journal of Molluscan Studies 69: 55-59.

Altman, K. A., S. H. Paull, P. T. J. Johnson, M. N. Golembieski, J. P. Stephens, B. E. LaFonte \& T. R. Raffel, 2016. Host and parasite thermal acclimation responses depend on the stage of infection. Journal of Animal Ecology 85: 1014-1024.

American Society for Testing and Materials (ASTM), 2013. Standard guide for conducting laboratory toxicity tests with freshwater mussels: E2455-06. ASTM International, West Conshohocken, Pennsylvania.

Bauer, G. \& K. Wächtler, 2001. Environmental relationships of naiads: threats, impact on the ecosystem, indicator function. In Bauer, G. \& K. Wächtler (eds), Ecology and Evolution of the Freshwater Mussels Unionoida. Ecological Studies, 145. Springer, Berlin.

Bjelke, U., U. Gärdenfors, A. Karlsson, S. Agrenius, M. Berggren, T. Cedhagen, H. G. Hansson, H. Kautsky, S. Lundberg, K. Lundin, T. Lundälv, T. von Proschwitz, C. Schander \& S. Smith, 2010. Blötdjur-Molluscs: Mollusca. In Gärdenfors, U. (ed.), Rödlistade arter i Sverige 2010. ArtDatabanken SLU, Uppsala: 495-505.

Blažek, R. \& M. Gelnar, 2006. Temporal and spatial distribution of glochidial larval stages of European unionid mussels (Mollusca: Unionidae) on host fishes. Folia Parasitologica 53: 98-106.
Bogan, A. E., 2008. Global diversity of freshwater mussels (Mollusca, Bivalvia) in freshwater. Hydrobiologia 595: 139-147.

Bradshaw, W. E., P. A. Zani \& C. M. Holzapfel, 2004. Adaptation to temperate climates. Evolution 58: 1748.

Brooks, D. R. \& E. P. Hoberg, 2007. How will global climate change affect parasite-host assemblages? Trends in Parasitology 23: 571-574.

Cohen, D., 1976. The optimal timing of reproduction. The American Naturalist 110: 801-807.

Comte, L. \& G. Grenouillet, 2013. Do stream fish track climate change? Assessing distribution shifts in recent decades. Ecography 36: 1236-1246.

Cope, W. G., R. B. Bringolf, D. B. Buchwalter, T. J. Newton, C. G. Ingersoll, N. Wang, T. Augspurger, F. J. Dwyer, M. C. Barnhart, R. J. Neves \& E. Hammer, 2008. Differential exposure, duration, and sensitivity of unionoidean bivalve life stages to environmental contaminants. Journal of the North American Benthological Society 27: 451-462.

Cosgrove, P. J., L. C. Hastie, J. Watt, I. Sime \& P. J. Boon, 2012. Scotland's freshwater pearl mussels: the challenge of climate change. In Boon, P. J. \& P. J. Raven (eds), River conservation and management. John Wiley \& Sons Ltd, Chichester, UK: 121-132.

Crozier, L. G. \& J. A. Hutchings, 2014. Plastic and evolutionary responses to climate change in fish. Evolutionary Applications 7: 68-87.

Cushing, D. H., 1990. Plankton production and year-class strength in fish populations: an update of the match/mismatch hypothesis. Advances in Marine Biology 26: 249-293.

Daraio, J. A., J. D. Bales \& T. J. Pandolfo, 2014. Effects of land use and climate change on stream temperature II: threshold exceedance duration projections for freshwater mussels. Journal of the American Water Resources Association 50: 1177-1190.

Davenport, D. \& M. Warmuth, 1965. Notes on the relationship between the freshwater mussel Anodonta implicata Say and the alewife Pomolobus pseudoharengus (Wilson). Limnology and Oceanography 10: R74-R78.

Domagała, J., L. Kirczuk \& M. Pilecka-Rapacz, 2013. Annual development cycle of gonads of Eurasian ruffe (Gymnocephalus cernuus L.) females from lower Odra River sections differing in the influence of cooling water. Journal of Freshwater Ecology 28: 423-437.

Dorts, J., G. Grenouillet, J. Douxfils, S. N. M. Mandiki, S. Milla, F. Silvestre \& P. Kestemont, 2012. Evidence that elevated water temperature affects the reproductive physiology of the European bullhead Cottus gobio. Fish Physiology and Biochemistry 38: 389-399.

Dytham, C., 2011. Choosing and Using Statistics: A Biologist's Guide, 3rd ed. Wiley, West Sussex.

Fritts, A. K., M. C. Barnhart, M. Bradley, N. Liu, W. G. Cope, E. Hammer \& R. B. Bringolf, 2014. Assessment of toxicity test endpoints for freshwater mussel larvae (glochidia). Environmental Toxicology and Chemistry 33: 199-207.

Galbraith, H. S., C. J. Blakeslee \& W. A. Lellis, 2012. Recent thermal history influences thermal tolerance in freshwater mussel species (Bivalvia: Unionoida). Freshwater Science 31: 83-92. 
Galbraith, H. S. \& C. C. Vaughn, 2009. Temperature and food interact to influence gamete development in freshwater mussels. Hydrobiologia 636: 35-47.

Ganser, A. M., T. J. Newton \& R. J. Haro, 2015. Effects of elevated water temperature on physiological responses in adult freshwater mussels. Freshwater Biology 60: 1705-1716.

Haag, W. R. \& M. L. Warren, 2000. Effects of light and presence of fish on lure display and larval release behaviours in two species of freshwater mussels. Animal Behaviour 60: 879-886.

Haas, W., 2003. Parasitic worms: strategies of host finding, recognition and invasion. Zoology 106: 349-364.

Hastie, L. C. \& M. R. Young, 2003. Timing of spawning and glochidia release in Scottish freshwater pearl mussel (Margaritifera margaritifera) populations. Freshwater Biology 48: 2107-2117.

Heinricher, J. R. \& J. B. Layzer, 1999. Reproduction by individuals of a nonreproducing population of Megalonaias nervosa (Mollusca: Unionidae) following translocation. The American Midland Naturalist 141: 140-148.

Hipfner, J. M., 2008. Matches and mismatches: ocean climate, prey phenology and breeding success in a zooplanktivorous seabird. Marine Ecology Progress Series 368: 295-304.

Hochwald, S., 1997. Das Beziehungsgefüge innerhalb der Größenwachstums- und Fortpflanzungsparameter bayrischer Bachmuschelpopulationen (Unio crassus Phil. 1788) und dessen Abhängigkeit von Umweltparametern. $\mathrm{PhD}$ thesis, Lehrstuhl für Tierökologie I der Universität Bayreuth.

IPCC, 2014. Climate change 2014: Synthesis report. Contribution of Working Groups I, II and III to the fifth assessment report of Intergovernmental Panel on Climate Change [Core Writing Team, R.K. Pachauri and L.A. Meyer (eds)]. Intergovernmental Panel on Climate Change (IPCC), Geneva.

Jansen, W., G. Bauer \& E. Zahner-Meike, 2001. Glochidial mortality in freshwater mussels. In Bauer, G. \& K. Wächtler (eds), Ecology and evolution of the freshwater mussels unionoida. Ecological Studies, 145. Springer, Berlin.

Jokela, J. \& P. Palokangas, 1993. Reproductive tactics in Anodonta clams: parental host recognition. Animal Behaviour 46: 618-620.

Lack, D., 1950. The breeding seasons of European birds. Ibis 92: 288-316.

Lang, K., 1998. Die Bachmuschel Unio crassus (PHILIPSSON, 1788) im Niederbach: Bestandssituation, Fortpflanzungsbiologie und Wanderverhalten. PhD thesis, Freiburg.

Lieth, H., 1974. Phenology and Seasonality Modeling. Ecological Studies, Analysis and Synthesis 8. Springer, Berlin.

Lopes-Lima, M., R. Sousa, J. Geist, D. C. Aldridge, R. Araujo, J. Bergengren, Y. Bespalaya, E. Bodis, L. Burlakova, D. van Damme, K. Douda, E. Froufe, D. Georgiev, C. Gumpinger, A. Karatayev, U. Kebapci, I. Killeen, J. Lajtner, B. M. Larsen, R. Lauceri, A. Legakis, S. Lois, S. Lundberg, E. Moorkens, G. Motte, K.-O. Nagel, P. Ondina, A. Outeiro, M. Paunovic, V. Prie, T. von Proschwitz, N. Riccardi, M. Rudzite, M. Rudzitis, C. Scheder, M. Seddon, H. Sereflisan, V. Simic, S. Sokolova, K. Stoeckl, J. Taskinen, A. Teixeira, F. Thielen, T. Trichkova, S. Varandas, H. Vicentini, K. Zajac, T. Zajac \& S. Zogaris, 2017. Conservation status of freshwater mussels in Europe: state of the art and future challenges. Biological Reviews of the Cambridge Philosophical Society 92: 572-607.

Lydeard, C., R. H. Cowie, W. F. Ponder, A. E. Bogan, P. Bouchet, S. A. Clark, K. S. Cummings, T. J. Frest, O. Gargomony, D. G. I. Herbert, R. Hershler, K. E. Perez, B. Roth, M. Seddon, E. E. Strong \& F. G. Thomson, 2004. The global decline of nonmarine mollusks. BioScience 54: 321.

Menzel, A., N. Estrella \& A. Testka, 2005. Temperature response rates from long-term phenological records. Climate Research 30: 21-28.

Meyers, T. R. \& R. E. Millemann, 1977. Glochidiosis of salmonid fishes. I. Comparative susceptibility to experimental infection with Margaritifera margaritifera (L.) (Pelecypoda: Margaritanidae). The Journal of Parasitology 63: 728.

Mordue (Luntz), A. J. \& M. A. Birkett, 2009. A review of host finding behaviour in the parasitic sea louse, Lepeophtheirus salmonis (Caligidae: Copepoda). Journal of Fish Diseases 32: 3-13.

Österling, E. M., 2015. Timing, growth and proportion of spawners of the threatened unionoid mussel Margaritifera margaritifera: influence of water temperature, turbidity and mussel density. Aquatic Sciences 77: 1-8.

Österling, E. M., L. A. Greenberg \& B. L. Arvidsson, 2008. Relationship of biotic and abiotic factors to recruitment patterns in Margaritifera margaritifera. Biological Conservation 141: 1365-1370.

Pandolfo, T. J., W. G. Cope, C. Arellano, R. B. Bringolf, M. C. Barnhart \& E. Hammer, 2010. Upper thermal tolerances of early life stages of freshwater mussels. Journal of the North American Benthological Society 29: 959-969.

Pandolfo, T. J., T. J. Kwak \& W. G. Cope, 2012. Thermal tolerances of freshwater mussels and their host fishes: species interactions in a changing climate. Walkerana: The Journal of the Freshwater Mollusk Conservation Society 15: 69-82.

Pankhurst, N. W. \& H. R. King, 2010. Temperature and salmonid reproduction: implications for aquaculture. Journal of Fish Biology 76: 69-85.

Pankhurst, N. W. \& P. L. Munday, 2011. Effects of climate change on fish reproduction and early life history stages. Marine and Freshwater Research 62: 1015.

Paull, S. H. \& P. T. J. Johnson, 2014. Experimental warming drives a seasonal shift in the timing of host-parasite dynamics with consequences for disease risk. Ecology letters 17: 445-453.

Poulin, R., 2007. Evolutionary Ecology of Parasites, 2nd ed. Princeton University Press, Princeton, New Jersey.

Reyjol, Y., J.-P. Léna, F. Hervant \& D. Pont, 2009. Effects of temperature on biological and biochemical indicators of the life-history strategy of bullhead Cottus gobio. Journal of Fish Biology 75: 1427-1445.

Roberts, A. D. \& M. C. Barnhart, 1999. Effects of Temperature, $\mathrm{pH}$, and $\mathrm{CO} 2$ on Transformation of the Glochidia of Anodonta suborbiculata on Fish Hosts and in Vitro. Journal of the North American Benthological Society 18: 475-487.

Runyon, J. B., M. C. Mescher \& C. M. de Moraes, 2006. Volatile chemical cues guide host location and host selection by parasitic plants. Science 313: 1964-1967.

Stenseth, N. C. \& A. Mysterud, 2002. Climate, changing phenology, and other life history traits: nonlinearity and match-mismatch to the environment. Proceedings of the 
National Academy of Sciences of the United States of America 99: 13379-13381.

Strayer, D. L., J. A. Downing, W. R. Haag, T. L. King \& J. B. Layzer, 2004. Changing perspectives on pearly mussels, North America's most imperiled animals. BioScience 54: 429-439.

Taeubert, J.-E., G. El-Nobi \& J. Geist, 2014. Effects of water temperature on the larval parasitic stage of the thick-shelled river mussel (Unio crassus). Aquatic Conservation: Marine and Freshwater Ecosystems 24: 231-237.

Tankersley, R. A. \& R. V. Dimock, 1993. The effect of larval brooding on the respiratory physiology of the freshwater unionid mussel Pyganodon cataracta. American Midland Naturalist 130: 146-163.

Teutsch, S., 1997. Populationsbiologische Untersuchung an Anodonta: Fortpflanzungsstrategien und Charakterisierung von Teilpopulationen innerhalb eines Stillgewässers. Diplomarbeit, Lehrstuhl Ökologie, Morphologie und Evolutionsbiologie, Universiät Freiburg (i. Breisgau).

Trübsbach, J., 1998. Fortpflanzungsbiologie und Mortalität der Gemeinen Teichmuschel Anodonta anatina (Linnaeus 1758). Diplomarbeit, Lehrstuhl Ökologie, Morphologie und Evolutionsbiologie, Universiät Freiburg (i. Breisgau).

Walther, G.-R., E. Post, P. Convey, A. Menzel, C. Parmesan, T. J. C. Beebee, J.-M. Fromentin, O. Hoegh-Guldberg \& F. Bairlein, 2002. Ecological responses to recent climate change. Nature 416: 389-395.

Watters, G. T., 2000. Freshwater mussels and water quality: a review of the effects of hydrologic and instream habitat alterations. Proceedings of the Conservation, Captive Care, and Propagation of Freshwater Mussels Symposium: 261-274.

Watters, G. T. \& S. H. O'Dee, 2000. Glochidial release as a function of water temperature: beyond bradyticty and tachyticity. Proceedings of the Conservation, Captive Care, and Propagation of Freshwater Mussels Symposium: 135-140.

Welte, R., 1999. Wirtserkennung bei der Teichmuschel Anodonta cygnea (L.) und der Bachmuschel Unio crassus (PHIL.). Diplomarbeit, Lehrstuhl Ökologie, Morphologie und Entwicklungsbiologie, Universität Freiburg (i. Breisgau).

Visser, M. E., A. J. Van Noordwijk, J. M. Tinbergen \& C. M. Lessells, 1998. Warmer springs lead to mistimed reproduction in great tits (Parus major). Proceedings of the Royal Society B: Biological Sciences 265: 1867-1870.

Young, M. \& J. Williams, 1984. The reproductive biology of the freshwater pearl mussel Margaritifera margaritifera (LINN.) in Scotland: I. Field studies. Archiv für Hydrobiologie 99: 405-422.

Zale, A. V. \& R. J. Neves, 1982. Fish hosts of four species of lampsiline mussels (Mollusca: Unionidae) in Big Moccasin Creek, Virginia. Canadian Journal of Zoology 60: 2535-2542.

Zimmerman, L. L. \& R. J. Neves, 2002. Effects of temperature on duration of viability for glochidia of freshwater mussels (Bivalvia: Unionidae). American Malacological Bulletin 17: 31-35. 